\title{
ABCA7 frameshift deletion associated with Alzheimer disease in African Americans
}

\section{OPEN}

Holly N. Cukier, PhD*

Brian W. Kunkle, PhD, $\mathrm{MPH}^{*}$

Badri N. Vardarajan, PhD*

Sophie Rolati, MS

Kara L.

Hamilton-Nelson, $\mathrm{MPH}$

Martin A. Kohli, PhD

Patrice L. Whitehead, BS

Beth A. Dombroski, PhD

Derek Van Booven, BS

Rosalyn Lang, PhD

Derek M. Dykxhoorn, $\mathrm{PhD}$

Lindsay A. Farrer, PhD

Michael L. Cuccaro, PhD Jeffery M. Vance, MD, $\mathrm{PhD}$

John R. Gilbert, PhD

Gary W. Beecham, PhD

Eden R. Martin, PhD

Regina M. Carney, MD

Richard Mayeux, MD, MSc

Gerard D. Schellenberg, $\mathrm{PhD}$

Goldie S. Byrd, PhD

Jonathan L. Haines, PhD

Margaret A.

Pericak-Vance, PhD

For the Alzheimer's

Disease Genetics

Consortium

Correspondence to Dr. Pericak-Vance: mpericak@med.miami.edu

Supplemental data at Neurology.org/ng

\section{ABSTRACT}

Objective: To identify a causative variant(s) that may contribute to Alzheimer disease (AD) in African Americans (AA) in the ATP-binding cassette, subfamily $A$ (ABC1), member 7 (ABCA7) gene, a known risk factor for late-onset $A D$.

Methods: Custom capture sequencing was performed on $\sim 150 \mathrm{~kb}$ encompassing ABCA7 in 40 AA cases and 37 AA controls carrying the AA risk allele (rs115550680). Association testing was performed for an ABCA7 deletion identified in large $A A$ data sets (discovery $n=1,068$; replication $n=1,749$ ) and whole exome sequencing of Caribbean Hispanic (CH) AD families.

Results: A 44-base pair deletion (rs142076058) was identified in all 77 risk genotype carriers, which shows that the deletion is in high linkage disequilibrium with the risk allele. The deletion was assessed in a large data set (531 cases and 527 controls) and, after adjustments for age, sex, and APOE status, was significantly associated with disease ( $p=0.0002$, odds ratio $[O R]=2.13$ [95\% confidence interval (CI): 1.42-3.20]). An independent data set replicated the association (447 cases and 880 controls, $p=0.0117$, OR $=1.65$ [95\% Cl: $1.12-2.44]$ ), and joint analysis increased the significance $\left(p=1.414 \times 10^{-5}\right.$, OR $=1.81[95 \% \mathrm{Cl}: 1.38-$ 2.37]). The deletion is common in AA cases (15.2\%) and AA controls (9.74\%), but in only $0.12 \%$ of our non-Hispanic white cohort. Whole exome sequencing of multiplex, $\mathrm{CH}$ families identified the deletion cosegregating with disease in a large sibship. The deleted allele produces a stable, detectable RNA strand and is predicted to result in a frameshift mutation (p.Arg578Alafs) that could interfere with protein function.

Conclusions: This common ABCA7 deletion could represent an ethnic-specific pathogenic alteration in AD. Neurol Genet 2016;2:e79; doi: 10.1212/NXG.0000000000000079

\section{GLOSSARY}

$\mathbf{A A}=$ African Americans; $\mathbf{A B C}=$ ATP-binding cassette; $\mathbf{A D}=$ Alzheimer disease $; \mathbf{C H}=$ Caribbean Hispanic $; \mathbf{C l}=$ confidence interval; GATK = Genome Analysis Toolkit; GWAS = genome-wide association study; $\mathbf{O R}=$ odds ratio; $\mathbf{S N V}=$ singlenucleotide variant.

Alzheimer disease (AD) is the leading cause of dementia in the elderly. AD occurs at a higher frequency in minority populations, with estimates of $\mathrm{AD}$ being twice as frequent in African Americans (AA) compared with non-Hispanic white (NHW) populations. ${ }^{1,2} A P O E$ was the first gene associated with $\mathrm{AD}$ and the $\varepsilon 4$ allele confers an increased risk across populations. ${ }^{3,4}$ Although $A P O E \& 4$ occurs more frequently in AA than NHW, paradoxically, it has a lower effect

\footnotetext{
*These authors contributed equally to the manuscript.

From the John P. Hussman Institute for Human Genomics (H.N.C., B.W.K., S.R., K.L.H.-N., M.A.K., P.L.W., D.V.B., D.M.D., M.L.C., J.M.V., J.R.G., G.W.B., E.R.M., R.M.C., M.A.P.-V.), Department of Neurology (H.N.C., J.M.V., M.A.P.-V.), Dr. John T. Macdonald Foundation Department of Human Genetics (D.M.D., M.L.C., J.M.V., J.R.G., G.W.B., E.R.M., R.M.C.), Miller School of Medicine, University of Miami, FL; The Taub Institute for Research on Alzheimer's Disease and the Aging Brain (B.N.V., R.M.), Gertrude H. Sergievsky Center, Departments of Neurology, Psychiatry, and Epidemiology, College of Physicians and Surgeons, Columbia University, New York, NY; Department of Pathology and Laboratory Medicine (B.A.D., G.D.S.), University of Pennsylvania Perelman School of Medicine, Philadelphia, PA; Department of Biology (R.L., G. S.B., M.A.P.-V.), North Carolina A\&T State University, Greensboro, NC; Departments of Medicine, Neurology, Ophthalmology, Genetics \& Genomics, Epidemiology, and Biostatistics (L.A.F.), Boston University, MA; and Department of Epidemiology and Biostatistics (J.L.H.), Institute for Computational Biology, Case Western Reserve University School of Medicine, Cleveland, OH.

Coinvestigators are listed at Neurology.org/ng.

Funding information and disclosures are provided at the end of the article. Go to Neurology.org/ng for full disclosure forms. The Article Processing Charge was paid by the authors.

This is an open access article distributed under the terms of the Creative Commons Attribution-NonCommercial-NoDerivatives License 4.0 (CC BY-NC-ND), which permits downloading and sharing the work provided it is properly cited. The work cannot be changed in any way or used commercially.
} 
size in $A A . .^{5-7}$ Therefore, while differing ethnicities share risk genes and alleles, the consequences may be different in distinct populations.

Recent studies have identified $>20$ additional loci associated with late-onset $\mathrm{AD}$, including $A B C A 7 .^{8-10}$ Although $A B C A 7$ was first implicated in NHW, a genome-wide significant signal was also detected in AA individuals at rs115550680, a position in linkage disequilibrium with the NHW genome-wide association study (GWAS) hits. ${ }^{8,9,11}$ The AA allele confers a higher risk $\left(p=2.21 \times 10^{-9}\right.$, odds ratio $[\mathrm{OR}]=1.79[95 \%$ confidence interval (CI): 1.47-2.12]) than the most significantly associated alleles in NHW..$^{7-9,11}$ The effect size of the AA $A B C A 7$ allele is comparable to $A P O E \& 4$ in $\mathrm{AA}\left(p=5.5 \times 10^{-47}\right.$, $\mathrm{OR}=2.31[95 \% \mathrm{CI}: 2.19-2.42]) \cdot{ }^{7,11}$ To date, there is no evidence of a functional consequence of the $\mathrm{AA} A B C A 7$ risk allele. ${ }^{12-15}$ Therefore, targeted sequencing of $A B C A 7$ was performed to identify potential causative variants. A frameshift deletion was found associated with $\mathrm{AD}$ in $\mathrm{AA}$, but was virtually absent in NHW. Thus, this deletion potentially represents a common, ethnic-specific, and likely pathogenic alteration that confers risk to $\mathrm{AD}$.

METHODS Standard protocol approvals, registrations, and patient consents. All the individuals ascertained for this study provided written informed consent prior to their inclusion. If a study participant was not competent to provide consent, the immediate next of kin or a legal representative provided written consent on the behalf of the participant. All participants were ascertained using a protocol that was approved by the appropriate Institutional Review Board. Oversight of this study falls under the University of Miami Institutional Review Board \#20070307.

Sample collection. African Americans. Individuals were ascertained for this study after they provided informed consent at the John P. Hussman Institute for Human Genomics (HIHG) at the University of Miami Miller School of Medicine (Miami, FL), North Carolina A\&T State University (Greensboro, NC), and Case Western Reserve University (Cleveland, OH) for the HIHG data set. Each of the participants was ascertained using the protocol approved by the proper institutional review boards (IRBs). Patients were collected for this study over the course of 10 years, with IRB protocols and amendments being approved at each stage. For the HIHG cohort (discovery), 539 cases were ascertained ( 415 women and 124 men, mean age at onset 74.0 years [SD 8.5]) and 529 controls ( 403 women and 126 men, mean age at examination 73.1 years [SD 5.4]). The complete HIHG casecontrol AA cohort $(\mathrm{n}=1,068)$ included 47 relatives, giving 1,021 independent (unrelated) individuals available for analysis.

Samples from the Alzheimer's Disease Genetics Consortium (ADGC) were collected as described previously. ${ }^{11}$ For the ADGC cohort (replication), 687 unrelated cases were ascertained (499 women and 188 men, mean age at onset 78.7 years [SD 8.5]) and 1,062 unrelated controls (774 women and 288 men, mean age at examination 78.6 years [SD 6.7]). This subset of the ADGC cohort was independent from the HIHG cohort.

For both HIHG and ADGC data sets, participants underwent rigorous phenotyping and diagnostic criteria following those of the National Institute of Neurological and Communicative Disorders and Stroke-Alzheimer's Disease and Related Disorders Association, as described previously. ${ }^{11,15,16}$ Furthermore, the cognitive status of controls was measured with either the MiniMental State Examination (MMSE) ${ }^{17}$ or the Modified MiniMental State $(3 \mathrm{MS})^{18}$ and the Clinical Dementia Rating Scale, which assesses functional decline. ${ }^{19}$ All the individuals in both cohorts enrolled self-identified as African American. These data were confirmed by analysis of existing GWAS data. ${ }^{11}$

Caribbean Hispanics. Nineteen multiplex Caribbean Hispanic $(\mathrm{CH})$ families initially recruited as a part of the Genetic Epidemiology of Alzheimer's Disease In Hispanics family study at Columbia University were included. A total of 49 cases and 8 unaffected relatives were involved in this study. Information about patient recruitment, demographics, and clinical phenotyping has been published previously. ${ }^{20}$ Each family has at least one member with early-onset $\mathrm{AD}$ (age at onset $<65$ years old).

Custom capture and whole exome sequencing. Custom sequence capture was performed on 77 HIHG samples of African American ancestry ( 40 cases and 37 controls) all with the AA risk allele. Probes were selected using the Agilent SureDesign program across the region (chr19:983277-1133190, $150 \mathrm{~kb}$; Agilent Technologies, Santa Clara, CA). Fourteen thousand six hundred thirty-six probes were chosen at a $3 \times$ density with the moderately stringent masking setting to cover $84.8 \%$ of the region. For whole exome sequencing, samples from the $19 \mathrm{CH}$ families were used (46 cases and 6 unaffected relatives). Capture and sequence library construction was performed on a Sciclone G3 NGS Workstation (Caliper Life Sciences, PerkinElmer, Waltham, MA) using the SureSelect Human All Exon 50 Mb Kit (Agilent Technologies) and the Paired-End Multiplexed Sequencing library kit (Illumina, San Diego, CA) for sequence library preparation. All samples were run on the Illumina HiSeq 2000 and paired-end $2 \times 100$ sequencing was performed. The sequencing data were processed using the Illumina Real-Time Analysis base calling pipeline version 1.8. The BurrowsWheeler Aligner was used to map sequences to the hg19 human reference genome, and variant calling was performed with the Genome Analysis Toolkit $\left(\right.$ GATK $\left.^{21,22}\right)$. GATK parameters included base quality score recalibration and duplicate removal. ${ }^{23}$ The data were evaluated for deletions and insertions by alignment with Bowtie 2 and analysis using the Pindel program. ${ }^{24,25}$

Sanger sequencing. Both the $A B C A 7$ deletion (rs142076058) and the AA $A B C A 7$ risk allele (rs115550680) were sequenced using traditional Sanger sequencing. Custom primers were designed with the Primer3 v4.0 program (http://fokker.wi.mit. edu/primer3/input.htm). For the deletion, primers were selected to flank the 44-base pair (bp) deletion to perform Sanger sequencing for validation (deletion-F: AAATCTTC CCGCCTTGAGAT, deletion-R: GGAGCTTAGGGTGC AGCTC). PCR experiments were set up with $1.5 \mathrm{mM}$ $\mathrm{MgCl}_{2}, 1.6 \mathrm{M}$ betaine, and touchdown PCR was performed. PCR experiments resulted in amplicons of either 450 or 406 bp. Sequencing of the AA risk allele was performed with the 
following primers (rs115550680-F: GCCAATATGGCAAAA CCATC, rs115550680-R: TCCAAAACCCTGTGATAGCC) to generate a 245 -bp amplicon. PCR reactions were set up with $2 \mathrm{mM} \mathrm{MgCl} 2$ and touchdown PCR was performed. Sequencing reactions were performed using the Big Dye Terminator v3.1 (Life Technologies, Carlsbad, CA), reactions were run on a 3730xl DNA Analyzer (Life Technologies), and results were evaluated using the Sequencher v4.10.1 program (Gene Codes Corporation, Ann Arbor, MI).

TaqMan SNP genotyping analysis. Both the $A B C A 7$ deletion (rs142076058) and the AA ABCA7 risk allele (rs115550680) were evaluated using the TaqMan singlenucleotide polymorphism (SNP) Genotyping Assays (Life Technologies). The ABCA7 deletion was evaluated by a custom-designed TaqMan SNP Genotyping Assays designed to recognize the presence or absence of the deletion. This assay had to be ordered as a "non-Human Assay" (forward primer: GCCTGGATCTACTCCGTGAC, reverse primer: GAGGCAGCTGAGGAACCA, FAM probe: GAGACGCGGCTGG-identifies when the sequence is deleted, VIC probe: CGCCATGGGGCT—wild-type allele). Samples were amplified for 40 cycles and, when amplification was low, an additional 20 cycles was added. The plates were read on the 7900HT Fast Real-Time PCR machine (Applied Biosystems, Foster City, CA), and data were analyzed with the SDS v2.4 software.

RNA isolation and real-time PCR. RNA was isolated from blood collected in PAXgene blood RNA tubes (PreAnalytiX, Hombrechtikon, Switzerland) from 10 samples with and 10 samples without the $A B C A 7$ deletion and extracted following the manufacturer's standard protocol. RNA was quantified on the 2100 BioAnalyzer (Agilent Technologies) and was required to have an RIN $\geq 6$. Complementary DNA (cDNA) libraries were generated using the iScript Reverse Transcriptase Supermix for RT-qPCR kit (BIO-RAD). PCR primers were designed to amplify the cDNA across the deletion (cDNA-F:
TGTTCCTGCGTGTGCTGA, cDNA-R: AGCAGGAAGC TCTGGGTCAC) and the resulting PCR products resolved on a $2 \%$ agarose gel. The wild-type allele results in an amplicon of $316 \mathrm{bp}$, whereas the allele with the deletion produces a 272-bp amplicon.

Statistical analysis. The GENMOD program, as part of the SAS/STAT software, was used to perform the association tests under a logistic regression model. Association tests were performed with adjustments for age, sex, APOE status, and relatedness between samples (SAS Institute, Cary, NC). Conditional analysis was performed in PLINK. ${ }^{26}$ The Fisher exact test was used to evaluate the differences in the alleles frequency of the deletion between African and European populations reported in the ExAC database.

RESULTS We selected $40 \mathrm{AA} \mathrm{AD}$ cases and $37 \mathrm{AA}$ controls (aged $>65$ years) carrying the AA risk allele, rs115550680, to perform custom massively parallel sequencing of a $\sim 150-\mathrm{kb}$ region that includes $A B C A 7$ and 8 flanking genes and a small nuclear RNA. Samples were sequenced to an average depth of over 1,000 $\times$ and evaluated for single-nucleotide variants ( $\mathrm{SNVs}$ ) and insertions and deletions. One thousand one hundred twenty SNVs were detected by sequencing with 11 variants showing different frequencies in cases and controls ( $p<0.1$, table e-1 at Neurology.org/ng). In addition, a 44-base pair (bp) deletion (rs142076058, p.Arg578Alafs) located $\sim 3.5 \mathrm{~kb}$ upstream of the AA risk allele was identified in all 77 individuals, which suggests that it is in high linkage disequilibrium with the risk allele (figure 1).

To further evaluate the rs142076058 deletion, a custom TaqMan genotyping assay was designed to evaluate the deletion in our larger AA cohort,

Figure 1 Location of the deletion in the ABCA7 gene and protein

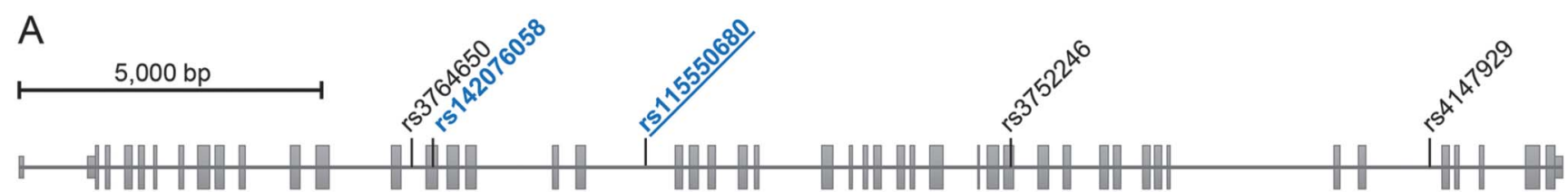

B

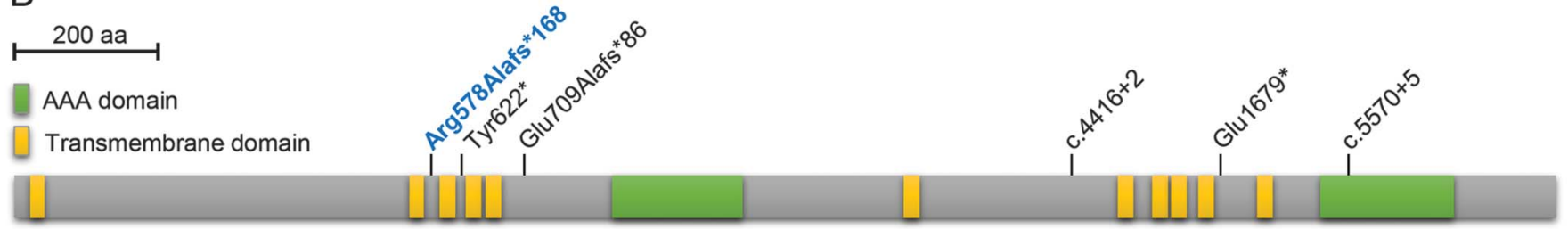

Arg578Alafs*168

(A) ABCA7 gene (chr19:1,040,103-1,065,571, hg38), 44-base pair deletion (blue), African American risk allele (blue and underlined ${ }^{11}$ ), and 3 non-Hispanic white (NHW) risk alleles (rs3764650, ${ }^{8}$ rs3752246, ${ }^{9}$ and rs414792910). (B) Wild-type ABCA7 protein (2,146 amino acids) and the location of frameshift deletion (blue) identified in this study. Below, the protein predicted to be generated from deletion would contain only 2 of the 11 transmembrane domains (yellow) and neither of the 2 AAA domains (green), but incorporate 168 aberrant amino acids (black). The remaining frameshift, nonsense, and splicing variants designated are rare alterations ( $<1 \%$ minor allele frequency) previously reported in NHW populations to be associated with Alzheimer disease. ${ }^{33-35}$ 


\begin{tabular}{|c|c|c|c|c|}
\hline \multirow[t]{2}{*}{ Table 1} & \multicolumn{4}{|c|}{ Association testing of the deletion in African American cohorts } \\
\hline & $\begin{array}{l}\text { Samples with deletion/ } \\
\text { total samples (\%) }\end{array}$ & OR & $95 \% \mathrm{Cl}$ & $\operatorname{Pr}>|Z|$ \\
\hline \multicolumn{5}{|l|}{ HIHG } \\
\hline Cases & $86 / 531$ (16.2) & 2.13 & $1.42-3.20$ & 0.0002 \\
\hline Controls & $49 / 527(9.3)$ & & & \\
\hline \multicolumn{5}{|l|}{ ADGC } \\
\hline Cases & $63 / 447$ (14.9) & 1.65 & $1.12-2.44$ & 0.0117 \\
\hline Controls & $88 / 880(10.0)$ & & & \\
\hline \multicolumn{5}{|c|}{ Joint analysis } \\
\hline Cases & 149/978 (15.2) & 1.81 & $1.38-2.37$ & $1.414 \times 10^{-5}$ \\
\hline Controls & $137 / 1,407$ (9.7) & & & \\
\hline
\end{tabular}

Abbreviations: $A D G C=$ Alzheimer's Disease Genetics Consortium; $\mathrm{Cl}=$ confidence interval; HIHG = John P. Hussman Institute for Human Genomics, University of Miami.

designated as HIHG. After adjustments for age, sex, and $A P O E$ status, the deletion was found to be significantly associated with $\mathrm{AD}(p=0.0002$, $\mathrm{OR}=$ 2.13 [95\% CI: 1.42-3.20], table 1) in 531 cases and 527 controls. The deletion occurred in $9.3 \%$ of control individuals but in $16.2 \%$ of AD cases. A subset of 8 individuals were pathologically confirmed cases of $\mathrm{AD} ; 2$ were found to carry the deletion whereas the remaining 6 did not. The AA risk allele was also genotyped in this data set. The risk allele was significantly associated with $\mathrm{AD}(p=0.0005, \mathrm{OR}=2.07$ [95\% CI: 1.38-3.13]) and in linkage disequilibrium with the deletion $\left(\mathrm{D}^{\prime}=1.000, r^{2}=0.995\right.$, tables e-2 and e-3). The top SNPs in $A B C A 7$ reported previously in NHW studies were also found to be in

\section{Figure 2 Pedigree of an AD family from the Dominican Republic with the ABCA7} deletion
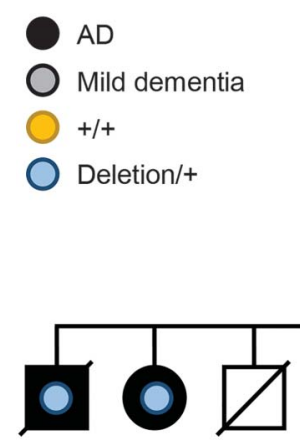

$$
5
$$

71

$3 / 4$

\section{$6 \quad 10$}

68

$3 / 3$

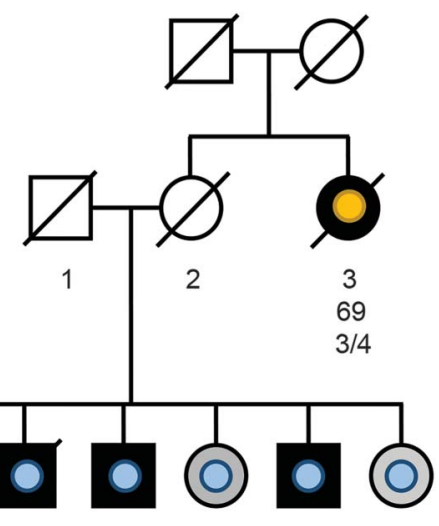

99

63

$3 / 4$

$\begin{array}{cccc}12 & 11 & 8 & 7 \\ 56 & 62 & 62 & 59 \\ 3 / 3 & 3 / 3 & 3 / 4 & 3 / 3\end{array}$

Family 360 has 6 individuals diagnosed with Alzheimer disease (AD) and 2 individuals presenting with mild dementia. The numbers beneath each individual in the pedigree represent the individual's sample number, the age at onset of $A D$ (for $A D$ cases) or the age at examination, and the APOE genotype. All 7 siblings carry the ABCA7 deletion and the African Americans (AA) risk allele, whereas individual 3 had neither the deletion nor the AA risk allele. linkage disequilibrium with the deletion (table e-4). ${ }^{8,9,11}$ Genotyping was also performed on our NHW AD samples $(\mathrm{n}=3,275)$, but only 4 individuals were identified with the deletion $(0.12 \%)$, all of whom carried the AA risk allele, which indicates that the genomic fragment carrying the deletion in these individuals may be of African descent.

An independent AA data set from the Alzheimer's Disease Genetics Consortium (ADGC) was evaluated in the same manner, and the deletion was again associated with $\mathrm{AD}(p=0.0117, \mathrm{OR}=$ 1.65 [95\% CI: 1.12-2.44], table 1), occurring in $10.0 \%$ of control individuals and $14.9 \%$ of $\mathrm{AD}$ cases. Joint analysis of the 2 cohorts increased the strength of the association $(p=1.414 \times$ $10^{-5}, \mathrm{OR}=1.81$ [95\% CI: $1.38-2.37$ ], table 1 ). Association testing was also performed for each data set without $A P O E$ adjustment; more significant results were obtained with $A P O E$ adjustment, demonstrating that $A P O E$ did not influence the association (table e-5). Examination of the ages of cases and controls with and without the deletion did not find a significant difference between any of these groups (table e-6).

To examine the association with $\mathrm{AD}$ in another ethnic group with a high level of African ancestry $(\sim 42 \%)$, we evaluated whole exome sequencing data on $19 \mathrm{CH}$ families from the Dominican Republic with multiple affected AD participants. ${ }^{27}$ In addition to a relatively high level of African ancestry, $\mathrm{CH}$ s are highly inbred and have a high incidence of $\mathrm{AD}$, and are thus enriched for $\mathrm{AD}$ genetic risk factors. ${ }^{28} \mathrm{We}$ independently identified the same 44-bp deletion from whole exome sequencing of 3 affected individuals from a large $\mathrm{CH}$ family. Subsequent examination of the family revealed that the deletion segregated in a large sibship in the family (figure 2). Both the deletion and AA risk allele were isolated in all 7 siblings who clinically presented in a range from $\mathrm{AD}$ (individuals $5,6,8,12$, and 99) to milder stages of dementia (individuals 7 and 11). Haplotype analysis around the $A B C A 7$ deletion using SNP data in the $1-\mathrm{Mb}$ flanking region on the family revealed that an affected aunt who does not carry the deletion, individual 3 (figure 2), has distinct ancestral haplotypes from the family members in the large sibship with the deletion (table e-7). This finding suggests that individual 3's $\mathrm{AD}$ phenotype can be attributed to other genetic factors and that the $A B C A 7$ deletion is highly penetrant in the sibship. Because several members of this $\mathrm{CH}$ family were known to have early-onset $\mathrm{AD}$ (age at onset $<65$ years), we examined the entire AA AD cohort (both HIHG and ADGC) to determine whether there was an effect of the deletion on age at onset in $\mathrm{AD}$. We found no 
difference in the age at onset in cases with the deletion (75.6 years [SD 9.6]) compared with cases absent for the deletion (76.8 years [SD 8.7], $p=0.09)$.

To determine whether the $A B C A 7$ allele with the deletion was being transcribed, RNA was isolated from the blood of AA individuals both with and without the $A B C A 7$ deletion. Reverse transcription PCR across the deletion region demonstrated that the allele carrying the deletion is transcribed and produces a stable detectable RNA strand (figure 3).

This deletion was reported previously in the Exome Aggregation Consortium (ExAC: http:// exac.broadinstitute.org) [June 2015], a repository of 60,706 unrelated individuals from 6 distinct ethnic groups. In the ExAC data set, the deletion was found in $7.77 \%$ of individuals of African ancestry and $0.95 \%$ of Latino individuals, but was absent from individuals of European ancestry. This difference in population frequencies between the African and European populations was highly significant $\left(p<1 \times 10^{-10}\right)$.

DISCUSSION We identified a 44-bp deletion in $A B C A 7$ that is associated with $\mathrm{AD}$ in individuals of African ancestry. Although the deletion did occur in unaffected individuals, it was found at a higher frequency in individuals with $\mathrm{AD}$ (15.2\% of cases vs $9.74 \%$ of controls), implicating it as a risk factor for disease. This reaffirms that the deletion is likely to be of African ancestry. Furthermore, the combined cases from the HIHG and ADGC data sets had the deletion at a frequency of $15.2 \%$, approximately twice as high as that identified with through ExAC African populations (7.8\%), lending additional evidence of a relationship to disease. The deletion was also independently identified in an $\mathrm{AD}$ family from the Dominican Republic, a population that has a relatively high level of African ancestry, $41.8 \% .{ }^{27}$ Examination of the linkage disequilibrium

Figure 3 Deletion allele produces an RNA transcript

A

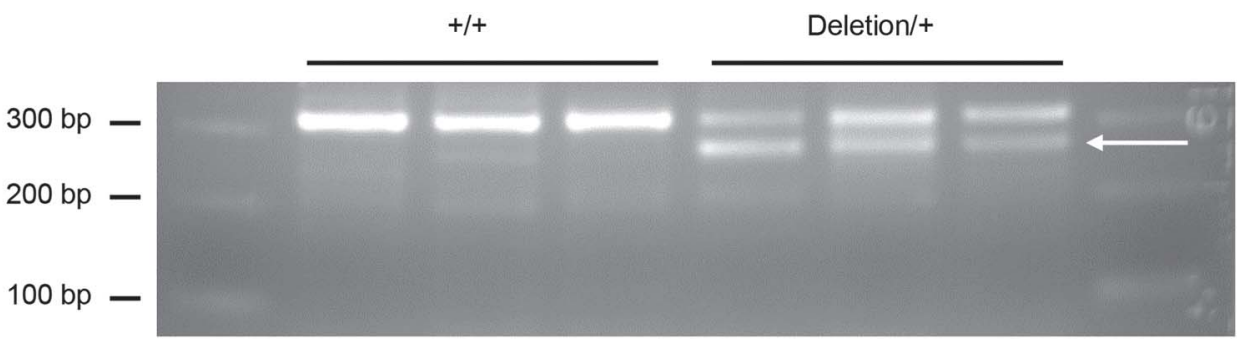

B

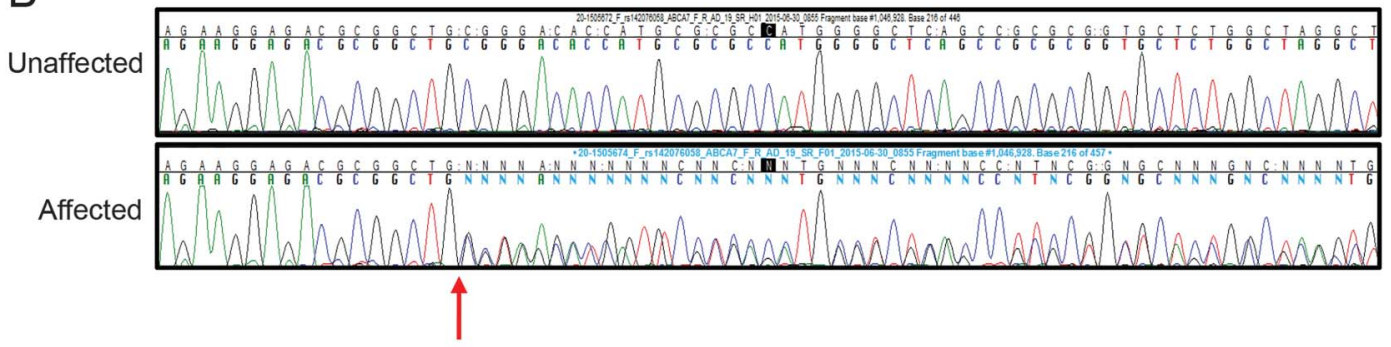

C

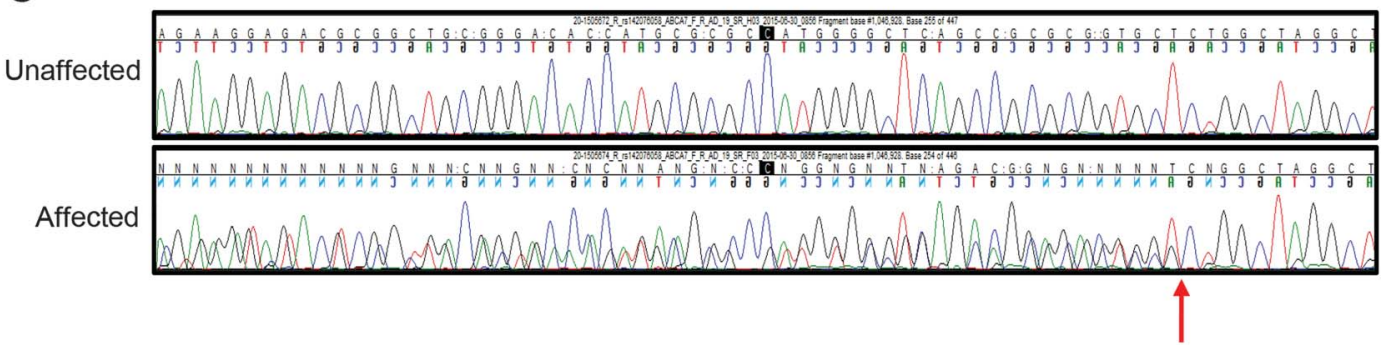

(A) Real-time PCR from cDNA of 3 samples without the $A B C A 7$ deletion $(+/+)$ and 3 samples heterozygous for the ABCA7 deletion (deletion/+). All samples produce an amplicon of 316 base pairs, but only the samples with deletion generate a lower, 272-base pair amplicon (arrow). (B) Sanger sequencing from the 5' end of the deletion in an African American control lacking the deletion and Alzheimer disease (AD)-specific line heterozygous for the deletion. The arrow denotes where the deleted allele begins to be out of frame with the wild-type allele C. Sanger sequencing from the $3^{\prime}$ end of the deletion from the same control and $A D$ individuals. 
of the deletion with the top 3 previously reported SNPs found a high $\mathrm{D}^{\prime}$ across all locations, but only a large $r^{2}$ with the African-specific risk allele (table e-4), further supporting that distinct alleles confer $\mathrm{AD}$ risk in different ethnicities. ${ }^{8,9,11}$

The deletion is predicted to cause a frameshift at amino acid 578, encoding for 168 incorrect amino acids before stopping prematurely compared with the largest isoform that generates a protein of 2,146 amino acids (figure 1B). Because we were able to detect RNA from the allele with the deletion, it is possible that this RNA generates an aberrant protein that interferes with the wild-type 2,146 amino acid protein. Within the first 578 amino acids, 2 transmembrane regions are conserved and would be maintained by the mutated protein (figure 1B). However, both AAA domains and 9 additional transmembrane domains would be predicted to be lost in this truncated protein, and thereby interfere with the protein's function of exporting the lipid phosphatidylserine. ${ }^{29}$ Alternatively, the shortened transcript may be subjected to nonsense-mediated decay (NMD), as was seen in the Glu709fs alteration identified in NHW. ${ }^{30}$ Although some loss-of-function variants in $A B C A 7$ were identified in NHW populations that may contribute to $\mathrm{AD}$ pathogenicity, these are rare variants and may only partially contribute to the NHW GWAS signal. ${ }^{30-32}$ A few previously reported lossof-function variants have demonstrated a functional consequence including the Glu709fs variant undergoing NMD, and the c. $5570+5 \mathrm{G}>\mathrm{C}$ alteration led to aberrant splicing ${ }^{30,31}$ (figure $1 \mathrm{~B}$ ). Therefore, this study may be the first to connect a potentially pathogenic and common alteration with a GWAS signal in $A B C A 7$.

$A B C A 7$ is a member of the ATP-binding cassette (ABC) transporter family, a large group of 49 genes that encode for membrane proteins that facilitate the movement of substrates across cell membranes. ${ }^{33,34}$ $A B C A 7$ is expressed in the brain in neurons and microglia. ${ }^{35,36}$ There is evidence both in patients and animal models demonstrating that inadequate levels of $A B C A 7$ may be directly correlated with Alzheimer pathogenesis. ${ }^{37-39}$ The ABCA7 protein is involved in the processing of amyloid precursor protein. ${ }^{40}$ In addition, evidence has shown that ABCA7 acts in the phagocytic pathway through extracellular signalregulated kinase signaling. ${ }^{\mathrm{e} 1, \mathrm{e} 2} A B C A 7$ is not the only $\mathrm{ABC}$ transporter gene linked to $\mathrm{AD} ; A B C A 1$, $A B C B 1, A B C C 1, A B C G 1, A B C G 2$, and $A B C G 4$ are all implicated in $A \beta$ regulation. ${ }^{\text {e3-e8 }}$ Furthermore, a study identified rare loss-of-function alterations in NHW patients diagnosed with Parkinson disease, including specific variants previously reported in $\mathrm{AD}$ individuals, which demonstrates that this gene may contribute to the risk of multiple neurodegenerative disorders. ${ }^{\text {9 }}$

Therefore, the results of this study demonstrate that there is a 44-bp deletion in $A B C A 7$ that is associated with $\mathrm{AD}$ and in linkage disequilibrium with the previously identified AA risk allele. The deletion was relatively frequent in our large $\mathrm{AA} A \mathrm{AD}$ cohorts, independently identified in 1 of $19 \mathrm{CH}$ AD families, and virtually absent from our large NHW AD cohort. Thus, the deletion could represent a common, ethnicspecific alteration that confers risk of $\mathrm{AD}$ in populations with African ancestry.

\section{AUTHOR CONTRIBUTIONS}

H.N.C., B.W.K., B.N.V., M.A.K., J.R.G., R.M., and M.A.P.-V. conceived and designed the experiments. R.L., M.L.C., J.M.V., R.M.C., G.S.B., J.L.H., and M.A.P.-V. acquired and assessed the HIHG samples. L.A.F., R.M., and G.D.S. acquired and assessed the ADGC samples. S.R., P.L.W., and B.A.D. performed custom capture sequencing, exome sequencing, Sanger sequencing, and TaqMan genotyping. H.N.C., B.W.K., B.N.V., S.R., K.L.H.-N., B.A.D., D.V.B., M.A.K., G.W.B., J.R.G., and M.A.P.-V. analyzed the sequencing and TaqMan data. B.W.K., K.L.H.-N., and M.A.P.-V. performed the statistical analysis. H.N.C., S.R., and D.M.D. performed RT-PCR. H.N.C. drafted the manuscript. B.W.K., B.N.V., D.M.D., J.M.V., G.W.B., M.A.K., R.M., G.D.S., J.L.H., and M.A.P.-V. edited the manuscript. The authors jointly discussed the experimental results throughout the duration of the study. All authors read and approved the final manuscript.

\section{ACKNOWLEDGMENT}

The authors acknowledge Doris Caldwell and Larry Deon Adams for their assistance in patient ascertainment and data management, and Anthony Griswold for his help in bioinformatics.

\section{STUDY FUNDING}

This research was supported by grants from the NIH [R01 AG027944, R01 AG028786 to M.A.P.-V., R01 AG019085 to J.L.H., P20 MD000546, R01 AG28786-01A1 to G.S.B., U01-AG032984, RC2-AG036528 to G.D.S., U24 AG026395, U24 AG026390, R01AG037212, R37 AG015473, R01AG015473 to R.M., R01 AG009029 to L.A.F., U01-AG016976 to W.A.K., U24-AG021886 to T.M.F., R01AG009956, RC2 AG036650 to K.H., UO1 AG06781, UO1 HG004610 to E.L., 5R01AG20688 to M.D.F., P50 AG005133, AG030653 to I.K., R01 AG1101, R01 AG030146, RC2 AG036650 to D.A.E., P30AG10161, R01AG15819, R01AG30146, R01AG17917, R01AG15819 to D.A.B., R01AG028786 to J.J.M., R01AG22018, P30AG10161 to L.L.B., P50AG16574, R01 032990, KL2 RR024151 to N.E.T. and N.R.G.R., AG005138 to J.D.B., P50 AG05681, P01 AG03991, P01 AG026276 to A.M.G., and U24AG041689 to L.S.W., and U19 AG047133 and UF1AG047133]; the Department of Defense [W81XWH-12-1-0013 to M.A.P.-V.]; a joint grant from the Alzheimer's Association [SG-14-312644] and the Fidelity Biosciences Research Initiative to M.A.P.-V.; and the BrightFocus Foundation [A2011048 to M.A.P.-V.].

\section{DISCLOSURE}

Dr. Cukier has received research support from the NARSAD Young Investigator Grant (The Brain \& Behavior Research Foundation), the Hussman Foundation, and the Alzheimer's Association. Dr. Kunkle reports no disclosures. Dr. Vardarajan has been a consultant for Immuneering Corporation. Ms. Rolati reports no disclosures. Ms. Hamilton-Nelson has received research support from NIH. Dr. Kohli, Ms. Whitehead, Dr. Dombroski, and Mr. Van Booven report no disclosures. Dr. Lang has served on the editorial board of the Journal of Parkinson's Disease and Alzheimer's Disease. Dr. Dykxhoorn has received research support from NIAID/NIH. Dr. Farrer has served on the editorial boards of the 
American Journal of Alzheimer's Disease \& Other Dementias and Clinical Genetics; holds a patent for Use of PLXNA4 as a drug target and biomarker for Alzheimer disease; has been a consultant for Novartis Pharmaceuticals, Gerson Lerman, and Guidepoint Global; has received research support from NIH, the Fidelity Foundation, and the Thome Memorial Foundation; and has been a consultant for Finnegan \& Associates LLP regarding legal proceedings. Dr. Cuccaro has served on the editorial board of Child Psychiatry \& Human Development. Dr. Vance has received honoraria from the University of Alaska (served on an NIH grant's internal review), and NEPTR, Department of Defense; has served on the editorial boards of the American Journal of Neurodegenerative Diseases and Neurology Genetics; holds patents for Method of detecting Charcot-Marie-Tooth disease type 2A, TRPC6 involved in glomerulonephritis, and Methods for identifying an individual at increased risk of developing coronary artery disease; has received research support from NIH/NINDS and the Hussman Foundation; and has received royalty payments from Duke University. Dr. Gilbert has been a consultant for Glenview NGLG; and has received research support from the Alzheimer's Association. Dr. Beecham has received research support from NIH and the Department of Defense. Dr. Martin has served on the editorial board of Frontiers in Statistical Genetics and Methodology; and holds US Patent No. 6697739-Test for Linkage and Association in General Pedigrees: The Pedigree Disequilibrium Test. Dr. Carney reports no disclosures. Dr. Mayeux has received research support through government grants RO1 AG037212 and RF1 AG015473. Dr. Schellenberg has served on the Alzheimer's Association Medical Advisory Board, Society of Progressive Supranuclear Palsy Scientific Advisory Board, Alzheimer Research Consortium Peebler PSP Research Foundation Medical and Scientific Advisory Committee, the Alzheimer's Association External Scientific Advisory Board, the scientific advisory board of the United Kingdom Parkinson Disease Center, the steering committee of the University College London, the Alzheimer's Disease Sequence Project, Structural Variant Work Group, the advisory committee of the Alzheimer's Disease Sequence Project, the Mayo Clinic Rochester Udall Center External Advisory Committee, the Discovery Assessment Panel of the University of Miami Udall Center, and the scientific advisory board of the Oxford Parkinson's Disease Centre; has received travel funding/speaker honoraria from the Alzheimer's Disease Center, CurePSP, the University of California, the 25th Annual Southern California Alzheimer's Disease Research Conference, the University of California Institute for Memory Impairment and Neurological Disorders, Biomarkers in Neuropsychiatric Disorders (Toronto, Canada), NIH, Novartis, the McKnight Brain Institute, the University of Florida, the Florida Alzheimer's Disease Center, the Lou Ruvo Center for Brain Health, the Accelerated Medicines Program Alzheimer's Disease, the University of Virginia, and Columbia University; has served on the editorial boards of the Journal of Neural Transmission, the American Journal of Alzheimer's Disease and other Dementias, Neurodegenerative Diseases, Current Alzheimer Research, and Pathology and Laboratory Medicine International; is an employee of the University of Pennsylvania; and has received research support from NIA/NIH, CurePSP, and CBD Solutions. Dr. Byrd reports no disclosures. Dr. Haines has received travel funding/speaker honoraria from Novartis; has served on the editorial boards of Neurogenetics, Current Protocols in Human Genetics, and Human Molecular Genetics; has received royalties from John Wiley \& Sons; has received research support from the NIH/NIA Consortium for Alzheimer's Sequence Analysis (CASA) and NIH/NEI; and has received royalty payments from Athena Diagnostics. Dr. Pericak-Vance reports no disclosures. Go to Neurology.org/ng for full disclosure forms.

Received January 5, 2016. Accepted in final form March 31, 2016.

\section{REFERENCES}

1. Green RC, Cupples LA, Go R, et al. Risk of dementia among white and African American relatives of patients with Alzheimer disease. JAMA 2002;287:329-336.

2. Chin AL, Negash S, Hamilton R. Diversity and disparity in dementia: the impact of ethnoracial differences in Alzheimer disease. Alzheimer Dis Assoc Disord 2011; 25:187-195.
3. Strittmatter WJ, Saunders AM, Schmechel D, et al. Apolipoprotein E: high-avidity binding to beta-amyloid and increased frequency of type 4 allele in late-onset familial Alzheimer disease. Proc Natl Acad Sci U S A 1993;90: 1977-1981.

4. Corder EH, Saunders AM, Strittmatter WJ, et al. Gene dose of apolipoprotein $\mathrm{E}$ type 4 allele and the risk of Alzheimer's disease in late onset families. Science 1993; 261:921-923.

5. Murrell JR, Price B, Lane KA, et al. Association of apolipoprotein E genotype and Alzheimer disease in African Americans. Arch Neurol 2006;63:431-434.

6. Ward A, Crean S, Mercaldi CJ, et al. Prevalence of apolipoprotein E4 genotype and homozygotes (APOE e4/4) among patients diagnosed with Alzheimer's disease: a systematic review and meta-analysis. Neuroepidemiology 2012;38:1-17.

7. Reitz C, Mayeux R. Genetics of Alzheimer's disease in Caribbean Hispanic and African American populations. Biol Psychiatry 2014;75:534-541.

8. Hollingworth P, Harold D, Sims R, et al. Common variants at ABCA7, MS4A6A/MS4A4E, EPHA1, CD33 and $\mathrm{CD} 2 \mathrm{AP}$ are associated with Alzheimer's disease. Nat Genet 2011;43:429-435.

9. Naj AC, Jun G, Beecham GW, et al. Common variants at MS4A4/MS4A6E, CD2AP, CD33 and EPHA1 are associated with late-onset Alzheimer's disease. Nat Genet 2011;43:436-441.

10. Lambert JC, Ibrahim-Verbaas CA, Harold D, et al. Metaanalysis of 74,046 individuals identifies 11 new susceptibility loci for Alzheimer's disease. Nat Genet 2013;45: $1452-1458$.

11. Reitz C, Jun G, Naj A, et al. Variants in the ATP-binding cassette transporter (ABCA7), apolipoprotein E 4, and the risk of late-onset Alzheimer disease in African Americans. JAMA 2013;309:1483-1492.

12. ENCODE Project Consortium, Dunham I, Kundaje A, et al. An integrated encyclopedia of DNA elements in the human genome. Nature 2012;489:57-74.

13. Kircher M, Witten DM, Jain P, O'Roak BJ, Cooper GM, Shendure J. A general framework for estimating the relative pathogenicity of human genetic variants. Nat Genet 2014; 46:310-315.

14. Shihab HA, Rogers MF, Gough J, et al. An integrative approach to predicting the functional effects of non-coding and coding sequence variation. Bioinformatics 2015;31: 1536-1543.

15. McKhann G, Drachman D, Folstein M. Clinical diagnosis of Alzheimer's disease: report of the NINCDS-ADRDA work group under the auspices of the Department of Health and human Services Task Force on Alzheimer's disease. Neurology 1984;34:939-944.

16. McKhann GM, Knopman DS, Chertkow H, et al. The diagnosis of dementia due to Alzheimer's disease: recommendations from the National Institute on AgingAlzheimer's Association workgroups on diagnostic guidelines for Alzheimer's disease. Alzheimers Dement 2011;7:263-269.

17. Folstein MF, Folstein SE, McHugh PR. "Mini-mental state." A practical method for grading the cognitive state of patients for the clinician. J Psychiatr Res 1975;12: 189-198.

18. Teng EL, Chui HC. The modified mini-mental state (3MS) examination. J Clin Psychiatry 1987;48:314-318. 
19. Morris JC. The clinical dementia rating (CDR): current version and scoring rules. Neurology 1993;43:2412-2414.

20. Lee JH, Cheng R, Barral S, et al. Identification of novel loci for Alzheimer disease and replication of CLU, PICALM, and BIN1 in Caribbean Hispanic individuals. Arch Neurol 2011;68:320-328.

21. Li H, Durbin R. Fast and accurate short read alignment with Burrows-Wheeler transform. Bioinformatics 2009; 25:1754-1760.

22. McKenna A, Hanna M, Banks E, et al. The Genome Analysis Toolkit: a MapReduce framework for analyzing next-generation DNA sequencing data. Genome Res 2010;20:1297-1303.

23. DePristo MA, Banks E, Poplin R, et al. A framework for variation discovery and genotyping using next-generation DNA sequencing data. Nat Genet 2011;43:491-498.

24. Ye K, Schulz MH, Long Q, Apweiler R, Ning Z. Pindel: a pattern growth approach to detect break points of large deletions and medium sized insertions from paired-end short reads. Bioinformatics 2009;25:2865-2871.

25. Langmead B, Salzberg SL. Fast gapped-read alignment with Bowtie 2. Nat Methods 2012;9:357-359.

26. Purcell S, Neale B, Todd-Brown K, et al. PLINK: a tool set for whole-genome association and population-based linkage analyses. Am J Hum Genet 2007;81:559-575.

27. Bryc K, Velez C, Karafet T, et al. Colloquium paper: genome-wide patterns of population structure and admixture among Hispanic/Latino populations. Proc Natl Acad Sci USA 2010;107(suppl 2):8954-8961.

28. Vardarajan BN, Schaid DJ, Reitz C, et al. Inbreeding among Caribbean Hispanics from the Dominican Republic and its effects on risk of Alzheimer disease. Genet Med 2014;17:639-643.

29. Quazi F, Molday RS. Differential phospholipid substrates and directional transport by ATP-binding cassette proteins $\mathrm{ABCA} 1, \mathrm{ABCA7}$, and ABCA4 and disease-causing mutants. J Biol Chem 2013;288:34414-34426.

30. Cuyvers E, De Roeck A, Van den Bossche T, et al. Mutations in ABCA7 in a Belgian cohort of Alzheimer's disease patients: a targeted resequencing study. Lancet Neurol 2015;14:814-822.

31. Steinberg S, Stefansson H, Jonsson T, et al. Loss-of-function variants in ABCA7 confer risk of Alzheimer's disease. Nat Genet 2015;47:445-447.

32. Vardarajan BN, Ghani M, Kahn A, et al. Rare coding mutations identified by sequencing of Alzheimer's disease GWAS loci. Ann Neurol 2015;78:487-498.

33. Kaminski WE, Orso E, Diederich W, Klucken J, Drobnik W, Schmitz G. Identification of a novel human sterol-sensitive ATP-binding cassette transporter (ABCA7). Biochem Biophys Res Commun 2000;273:532-538.

34. Pahnke J, Frohlich C, Krohn M, Schumacher T, Paarmann K. Impaired mitochondrial energy production and $\mathrm{ABC}$ transporter function-A crucial interconnection in dementing proteopathies of the brain. Mech Ageing Dev 2013;134:506-515.

35. Langmann T, Mauerer R, Zahn A, et al. Real-time reverse transcription-PCR expression profiling of the complete human ATP-binding cassette transporter superfamily in various tissues. Clin Chem 2003;49:230-238.

36. Kim WS, Guillemin GJ, Glaros EN, Lim CK, Garner B. Quantitation of ATP-binding cassette subfamily-A transporter gene expression in primary human brain cells. Neuroreport 2006;17:891-896.

37. Logge W, Cheng D, Chesworth R, et al. Role of Abca7 in mouse behaviours relevant to neurodegenerative diseases. PLoS One 2012;7:e45959.

38. Vasquez JB, Fardo DW, Estus S. ABCA7 expression is associated with Alzheimer's disease polymorphism and disease status. Neurosci Lett 2013;556:58-62.

39. Kim WS, Li H, Ruberu K, et al. Deletion of Abca7 increases cerebral amyloid-beta accumulation in the J20 mouse model of Alzheimer's disease. J Neurosci 2013; 33:4387-4394.

40. Chan SL, Kim WS, Kwok JB, et al. ATP-binding cassette transporter A7 regulates processing of amyloid precursor protein in vitro. J Neurochem 2008;106:793-804. 


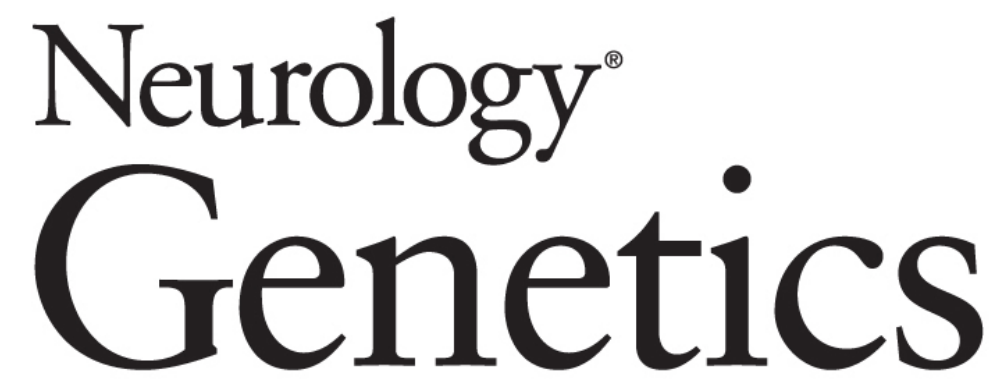

$A B C A 7$ frameshift deletion associated with Alzheimer disease in African Americans Holly N. Cukier, Brian W. Kunkle, Badri N. Vardarajan, et al. Neurol Genet 2016;2;

DOI 10.1212/NXG.0000000000000079

This information is current as of May 17, 2016

Neurol Genet is an official journal of the American Academy of Neurology. Published since April 2015, it is an open-access, online-only, continuous publication journal. Copyright ( 2016 American Academy of Neurology. All rights reserved. Online ISSN: 2376-7839.

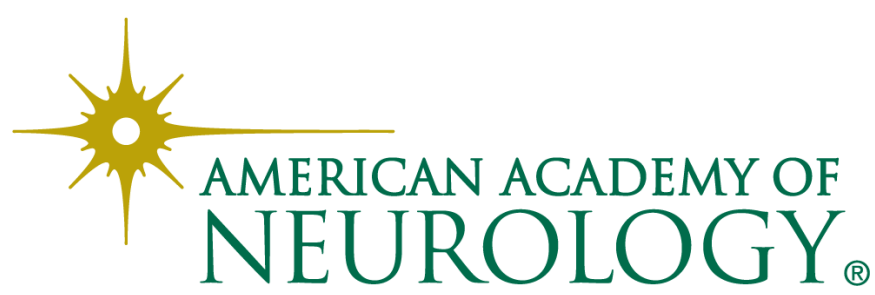




\section{Updated Information \& Services}

\section{Supplementary Material}

\section{References}

Citations

Subspecialty Collections

\section{Permissions \& Licensing}

\section{Reprints}

including high resolution figures, can be found at: http://ng.neurology.org/content/2/3/e79.full.html

Supplementary material can be found at: http://ng.neurology.org/content/suppl/2016/05/17/2.3.e79.DC1 http://ng.neurology.org/content/suppl/2016/05/17/2.3.e79.DC2

This article cites 40 articles, 7 of which you can access for free at: http://ng.neurology.org/content/2/3/e79.full.html\#\#ref-list-1

This article has been cited by 7 HighWire-hosted articles: http://ng.neurology.org/content/2/3/e79.full.html\#\#otherarticles

This article, along with others on similar topics, appears in the following collection(s):

All Genetics

http://ng.neurology.org//cgi/collection/all_genetics

\section{Alzheimer's disease}

http://ng.neurology.org//cgi/collection/alzheimers_disease

Association studies in genetics

http://ng.neurology.org//cgi/collection/association_studies_in_genetics

Information about reproducing this article in parts (figures,tables) or in its entirety can be found online at:

http://ng.neurology.org/misc/about.xhtml\#permissions

Information about ordering reprints can be found online: http://ng.neurology.org/misc/addir.xhtml\#reprintsus

Neurol Genet is an official journal of the American Academy of Neurology. Published since April 2015, it is an open-access, online-only, continuous publication journal. Copyright ( 2016 American Academy of Neurology. All rights reserved. Online ISSN: 2376-7839.

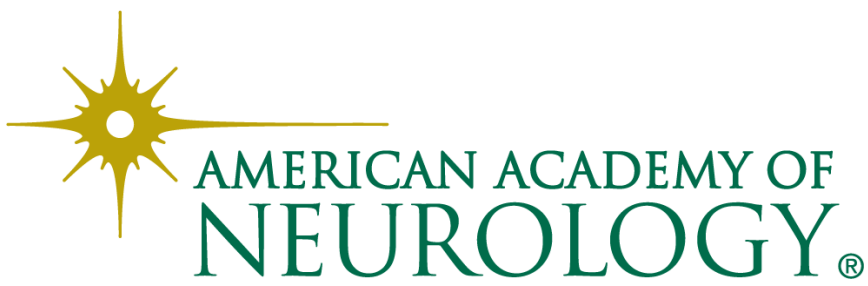

